\title{
Screening, Counseling, and Shared Decision Making for Alcohol Use with Transgender and Gender-Diverse Populations
}

\author{
Jacob Arellano-Anderson ${ }^{1}$ and Alex S. Keuroghlian, MD, MPH ${ }^{1-3}$
}

\begin{abstract}
At-risk alcohol use occurs among transgender and gender-diverse (TGD) populations, yet current alcohol use screening tools and guidelines do not distinguish between sex- and gender-related characteristics, having been developed without accounting for natal sex-based physiology, effects of gender-affirming medical care, and gendered drinking behavior among TGD people. More research on how sex- and gender-related factors independently influence alcohol use can help validate gender-inclusive screening protocols and develop evidence-based guidelines meaningful for people of all genders. In the interim, clinicians must be mindful of gender diversity and engage in transparent, collaborative discussions when screening for and counseling about alcohol use.
\end{abstract}

Keywords: alcohol, counseling, gender identity, nonbinary, screening, transgender

\section{Introduction}

$\mathbf{T}$ O DIFFERENTIATE WHETHER a patient is drinking alcohol in moderation, engaging in at-risk use, or struggling with an alcohol use disorder (AUD), a clinician might utilize established guidelines and screening tools. The National Institute on Alcohol Abuse and Alcoholism (NIAAA) and the Dietary Guidelines for Americans from the U.S. Department of Health and Human Services and U.S. Department of Agriculture (HHS and USDA), for example, define heavy drinking as 8 or more drinks a week for women and 15 or more drinks a week for men. ${ }^{1,2}$ These definitions and tools, however, are often developed based on assumptions of cisgender and binary gender identities and are therefore inadequate for clinicians trying to screen for and counsel about alcohol use with transgender and gender-diverse (TGD) patients. ${ }^{3,4}$

Consider a patient who is a transgender man, has been on masculinizing hormone therapy for 10 years, and drinks between 10 and 12 alcoholic beverages a week. Reviewing the NIAAA guidelines, ${ }^{1}$ the clinician concludes that given the patient's long-term masculinizing hormone therapy and increased muscle mass, one can reasonably apply NIAAA guidelines for heavy drinking among presumed cisgender men, ${ }^{1}$ provide psychoeducation based on these guidelines, and move on. Now, consider another scenario in which a patient instead identifies as nonbinary and trans masculine: like the first patient, they were assigned female sex at birth and re- port consuming between 10 and 12 alcoholic beverages a week. They began taking masculinizing hormone therapy 3 months ago and the clinician notes that this patient has less muscle mass than the first patient. The clinician worries that the patient's alcohol use may be too heavy and advises them to cut down. Yet, if this patient were to ask what the evidence is for this recommendation, what would the clinician say?

\section{Sex- and Gender-Related Factors in Alcohol Use}

To answer this question, clinicians may return to fundamental principles-understanding how sex- and genderrelated factors differentially drive alcohol risk. The NIAAA offers "typical" cutoffs based on gender (not distinguished from sex) and defines binge drinking as "a pattern of drinking that brings blood alcohol concentration (BAC) to 0.08 gram percent or above." ${ }^{5}$ Body fat and muscle composition are characteristics relevant to ethanol metabolism that vary across populations with different natal sex-based physiology and may also change based on ages of initiation and types of gender-affirming medical care among TGD people ${ }^{6}$ (Table $1^{1,2,5,7-10}$ ). As such, knowledge of the full history of gender-affirming care for each patient may seem heuristically instructive to clinicians (e.g., the duration of hormone therapies and their impact on a patient's metabolic profile), however rigorous evidence is lacking to guide interventions accordingly for TGD people.

\footnotetext{
${ }^{1}$ Department of Psychiatry, Harvard Medical School, Boston, Massachusetts, USA.

${ }^{2}$ Department of Psychiatry, Massachusetts General Hospital, Boston, Massachusetts, USA.

${ }^{3}$ National LGBTQIA+ Health Education Center, Division of Education and Training, The Fenway Institute, Fenway Health, Boston, Massachusetts, USA.
} 
Table 1. Selected Definitions and Guidelines for Unhealthy Alcohol Use and Their Limitations for Transgender and Gender-Diverse Populations

\begin{tabular}{|c|c|c|c|}
\hline Term & Agency & Definition & Limitations for TGD populations \\
\hline \multicolumn{4}{|l|}{ Gendered } \\
\hline $\begin{array}{l}\text { Moderate } \\
\text { drinking }\end{array}$ & $\begin{array}{l}\text { HHS and } \\
\text { USDA }\end{array}$ & $\begin{array}{l}\text { One drink per day for women and up to two } \\
\text { drinks per day for men. }\end{array}$ & \multirow{4}{*}{$\begin{array}{l}\text { Assumption of cisgender and binary } \\
\text { gender identities is exclusionary } \\
\text { toward TGD people. Unclear if } \\
\text { based on factors related to natal } \\
\text { sex-based physiology, or current } \\
\text { sex-based physiology, which may } \\
\text { vary for TGD people who have } \\
\text { accessed gender-affirming medical } \\
\text { or surgical care. }\end{array}$} \\
\hline $\begin{array}{l}\text { Heavy } \\
\text { drinking }\end{array}$ & $\begin{array}{l}\text { HHS and } \\
\text { USDA }\end{array}$ & $\begin{array}{l}\text { Alcohol consumption of } 8 \text { or more drinks a } \\
\text { week for women and } 15 \text { or more drinks a } \\
\text { week for men. }\end{array}$ & \\
\hline & NIAAA & $\begin{array}{l}\text { Alcohol consumption by men who drink more } \\
\text { than } 4 \text { standard drinks in a day (or more than } \\
14 / \text { week) and women who drink more than } \\
3 \text { in a day (or more than } 7 / \text { week). }\end{array}$ & \\
\hline $\begin{array}{l}\text { Binge } \\
\text { drinking }\end{array}$ & NIAAA & $\begin{array}{l}\text { A pattern of drinking that brings blood alcohol } \\
\text { concentration to } 0.08 \text { gram percent or above, } \\
\text { specified as typically occurring after four or } \\
\text { more drinks for women and five or more } \\
\text { drinks for men-in about } 2 \text { hours. }\end{array}$ & \\
\hline
\end{tabular}

Nongendered

\begin{tabular}{|c|c|c|c|}
\hline $\begin{array}{r}\text { Hazardous } \\
\text { drinking }\end{array}$ & WHO & $\begin{array}{l}\text { Quantity or pattern of alcohol consumption that } \\
\text { places individuals at risk for adverse health } \\
\text { events; often detected by a score of } \geq 8 \text { on the } \\
\text { AUDIT. }\end{array}$ & $\begin{array}{l}\text { Often detected by the AUDIT or the } \\
\text { MAST, which can be time } \\
\text { consuming to administer and are } \\
\text { not validated for TGD populations. }\end{array}$ \\
\hline $\begin{array}{l}\text { Harmful } \\
\text { drinking }\end{array}$ & WHO & $\begin{array}{l}\text { Alcohol consumption that results in physical or } \\
\text { psychological harm; often detected by a score } \\
\text { of }>15 \text { on the AUDIT, or by a score of } \geq 2 \text { on } \\
\text { the TWEAK during pregnancy. }\end{array}$ & $\begin{array}{l}\text { Other abbreviated instruments, } \\
\text { such as the 10-item Brief MAST, } \\
\text { the } 13 \text {-item Short MAST or } \\
\text { CAGE, are also not validated for }\end{array}$ \\
\hline $\begin{array}{l}\text { Alcohol } \\
\text { dependence }\end{array}$ & DSM-IV $^{9}$ & $\begin{array}{l}\text { Former psychiatric diagnosis referring to } \\
\text { individuals who are physically or } \\
\text { psychologically dependent upon alcohol. } \\
\text { Symptoms detected by questions } 4-6 \text { on the } \\
\text { AUDIT, or may be suggested by a score of } \geq 6 \\
\text { on the MAST. }\end{array}$ & $\begin{array}{l}\text { TGD populations, while the } \\
\text { AUDIT-C uses gendered cutoffs. } \\
\text { The TWEAK Alcohol Screening } \\
\text { Test is designed for presumed } \\
\text { cisgender women during } \\
\text { pregnancy and not validated for } \\
\text { pregnant TGD people. }\end{array}$ \\
\hline
\end{tabular}

Columns 1 through 3 are adapted with written permission from O'Connor et al. ${ }^{10}$

AUDIT-C, Alcohol Use Disorders Identification Test-Concise; CAGE, "Cutting down," being "Annoyed," feeling "Guilty," and having an "Eye-opener"; DSM-IV, Diagnostic and Statistical Manual of Mental Disorders, 4th Edition; HHS and USDA, U.S. Department of Health and Human Services and U.S. Department of Agriculture; MAST, Michigan Alcohol Screening Test; NIAAA, National Institute on Alcohol Abuse and Alcoholism; TGD, transgender and gender-diverse; TWEAK, Tolerance, Worried, Eye-opener, Amnesia, K/Cutdown; WHO, World Health Organization.

Furthermore, while social drinking patterns are gendered behaviors that may differ between presumed cisgender women and men, ${ }^{11,12}$ these patterns remain poorly understood for TGD communities. The nuance of how sex- and genderrelated factors differentially drive risk is rarely considered in the literature or guidelines pertaining to alcohol use, and this distinction is often unaddressed even in studies explicitly working with TGD communities. ${ }^{13}$ We know that TGD populations have different alcohol-related risks than their cisgender counterparts. In one study, transgender people had more frequent heavy drinking episodes compared with either cisgender women or men, ${ }^{14}$ whereas another found that nonbinary/genderqueer adolescents assigned male sex at birth had lower odds of recent alcohol use than their cisgender peers. ${ }^{15}$

\section{Use of Screening Tools for TGD Populations}

Consider another clinical scenario, in which the patient is a transgender woman. This time, the clinician utilizes the Alcohol Use Disorders Identification Test-Consumption (AUDIT-C), a three-item alcohol use screening tool that focuses on consumption to identify hazardous drinking. ${ }^{10}$ The clinician would face a similar challenge as before: for presumed men a score of $\geq 4$ is a positive screen, and for presumed women a score of $\geq 3$ is a positive screen. ${ }^{10}$ If the patient scores a 3 (Table $2^{7}$ ), a cautious approach might be to consider the screen positive, yet it is notable that existing studies even with the general population vary in their recommended gendered cutoffs with both the AUDIT-C and full AUDIT. ${ }^{16,17}$

Although the full 10-item AUDIT generally recognizes a score $\geq 8$ as a positive screen for alcohol risk regardless of gender, it has not yet been validated with TGD populations, despite the World Health Organization (WHO) guidance that "the test could be improved by focusing on more carefully defined risk groups [...] Specification of cut-off points is needed for $[\ldots]$ populations whose problems are to be the focus of screening with AUDIT.",7 Some studies have used 
Table 2. Alcohol Use Disorders Identification Test-Consumption (AUDIT-C) Conducted IN THE Context of the Clinical Scenario IN Which a Transgender Woman Scores a 3

Q1: How often did you have a drink containing alcohol in the past year? Points

Never

Monthly or less

Two to four times a month

Two to three times a month

Four or more times a week

0

1

3

4

Q2: How many drinks did you have on a typical

day when you were drinking in the past year?

\begin{tabular}{ll}
\hline None, I do not drink & 0 \\
1 or 2 & 0 \\
3 or 4 & $1 X$ \\
5 or 6 & 2 \\
6 to 9 & 3 \\
10 or more & 4
\end{tabular}

Q3: How often did you have six or more drinks on one occasion in the past year?

Never

Less than monthly

Monthly

Weekly

Daily or almost daily

Total Score

$0 \mathrm{X}$

AUDIT-C adapted with written permission from the WHO. WHO does not endorse any specific companies, products, or services. For presumed cisgender women, a score greater than or equal to three is considered a positive screen, and for presumed cisgender men, a score greater than or equal to four is considered a positive screen, ${ }^{10}$ however, there is currently no validated clinical cutoff score for transgender women. $\mathrm{X}$ indicates the patient's selected answer in response to each question item.

the AUDIT with TGD cohorts: in one Brazilian study, for example, $48.2 \%$ of transgender women had AUDIT scores $\geq 8$, which qualifies as "hazardous use" according to nongendered WHO guidelines. ${ }^{18}$ Another study from Peru with transgender women and with men who have sex with men found that, while $67 \%$ of participants self-reported binge drinking and $86 \%$ had biomarkers consistent with heavy alcohol use, only $25 \%$ screened positive on the AUDIT and only $6 \%$ did so on the CAGE screening questionnaire ("Cutting down," being "Annoyed," feeling "Guilty," and having an "Eye-opener"). ${ }^{19}$ Although this was a small cross-sectional study with methodological limitations, it called into question whether existing screening tools are accurately calibrated for detecting unhealthy alcohol use among all TGD populations.

\section{Future Alcohol Research for All Genders}

Research regarding alcohol use must systematically integrate both sex- and gender-related methodological considerations, as the current conflation of these factors is a primary barrier to gender-inclusive guidelines. ${ }^{13}$ AUD research must be specific and nuanced in defining and collecting data regarding: sex assigned at birth; developmental history of social, medical, and surgical gender affirmation; current gender identity; current sex-based physiology; and how each of these factors is related to longitudinal patterns of alcohol use. Ideally this information would be collected alongside BAC to assess how gender affirmation processes influence alcohol metabolism and then craft guidelines that better align with physiological parameters for unhealthy alcohol use, such as BAC $\geq 0.08 \mathrm{~g} / \mathrm{dL}$.

Short-term initiatives to aid clinical decision making could include validating existing screening tools in large and diverse cohorts of TGD populations. A recent study with gender minority participants offers a promising example, determining that consuming $\geq 5$ alcoholic beverages on one occasion in the past year was optimal in predicting harmful drinking (defined as a score of $\geq 8$ on the full AUDIT). ${ }^{20}$ Although this study offers clinicians evidence to guide brief screening, it still rests on the assumption that AUDIT thresholds are valid and effective in detecting unhealthy alcohol use for TGD populations. A review of screening tools within a traditional binary gender paradigm shows that AUDIT, CAGE, and other screening tools may perform differently with women and men, which raises questions about how to optimize their use with TGD people. ${ }^{21}$ We ought to improve alcohol use screening tools by expanding these to account for sex- and gender-related diversity beyond the binary paradigm that conflates these factors in two categories of female/woman or male/man. ${ }^{22}$

\section{Discussing Alcohol Use with TGD Patients}

In addition to the lack of guidelines to aid in detecting atrisk alcohol use among TGD people, there are insufficient data to inform alcohol-related clinical counseling and management for TGD populations. It remains unknown what inequities exist for TGD people in accessing effective treatments and services for AUDs, despite evidence suggesting that TGD people are more likely to want help in reducing substance use than their cisgender counterparts. ${ }^{23}$

Clinicians ought to incorporate available tools as much as possible in conversations about alcohol use with TGD patients. One approach may be to simply discuss current guidelines with the patient, acknowledging conflation of sex- and gender-related factors as well as presumed binary gender identities in the existing evidence base, and to collaboratively decide on personalized parameters for healthy alcohol use. Factors to consider may include the developmental impact of gender-affirming hormone therapies and surgeries, and the patient's self-report of their social drinking behaviors. Clinicians ought to discuss each of these topics through intersectional shared decision-making approaches that consider additional important aspects of the patient's identity, such as race or ethnicity. ${ }^{24}$

Furthermore, it is important for clinicians to develop skills in offering affirming psychoeducation and counseling for TGD populations around alcohol use, ${ }^{25}$ in parallel with robust attempts by the scientific community to generate gender-inclusive evidence to inform screening and intervention. Clinical conversations that center experiences of gender minority stress, and how these may contribute to a TGD patient's alcohol use, ${ }^{26}$ can help guide tailored motivational enhancement approaches, as well as referrals 
to behavioral health services, TGD-affirming harm reduction and sobriety programs, and community-based TGD support groups, regardless of whether the patient meets quantitative threshold criteria on existing alcohol use screening tools.

\section{Conclusion}

Despite unique considerations regarding at-risk alcohol use and alcohol-related adverse outcomes among TGD communities, research is lacking to adequately guide shared clinical decision making about alcohol use with TGD patients. Future alcohol research must make distinctions between sex- and gender-related factors, screening tools must be validated for TGD populations, and guidelines must be nuanced in their inclusivity of TGD populations. Although clinicians may not currently have evidence or tools necessary to provide optimal screening and counseling for alcohol use with TGD patients, we have an obligation to combine critical appraisal of extant literature, layered understanding of gender diversity, and the self-knowledge of each TGD patient to offer collaborative and affirming care that promotes healthy alcohol-related behaviors.

\section{Author Disclosure Statement}

A.S.K. stands to receive royalties as editor of a forthcoming textbook on TGD health published by McGraw-Hill Education. The authors have no other relevant disclosures.

\section{Funding Information}

This research was supported by grant U30CS22742 from the Health Resources and Services Administration Bureau of Primary Health Care.

\section{References}

1. National Institute on Alcohol Abuse and Alcoholism. Helping patients who drink too much: A clinician's guide. 2005. Available at https://pubs.niaaa.nih.gov/publications/prac titioner/cliniciansguide2005/guide.pdf Accessed August 6, 2020.

2. U.S. Department of Health and Human Services and U.S. Department of Agriculture. 2015-2020 Dietary Guidelines for Americans. 8th ed. Washington, DC, 2015. Available at https://health.gov/sites/default/files/2019-09/2015-2020_ Dietary_Guidelines.pdf Accessed August 6, 2020.

3. Talley AE, Gilbert PA, Mitchell J, et al.: Addressing gaps on risk and resilience factors for alcohol use outcomes in sexual and gender minority populations. Drug Alcohol Rev 2016;35:484-493.

4. Keuroghlian AS, Reisner SL, White JM, Weiss RD: Substance use and treatment of substance use disorders in a community sample of transgender adults. Drug Alcohol Depend 2015;152:139-146.

5. National Institute on Alcohol Abuse and Alcoholism. NIAAA council approves definition of binge drinking. NIAAA Newsletter 2004;3:3. Available at https://pubs .niaaa.nih.gov/publications/Newsletter/winter2004/Newslet ter_Number3.pdf Accessed August 13, 2020.

6. Wiik A, Andersson DP, Brismar TB, et al.: Metabolic and functional changes in transgender individuals following cross-sex hormone treatment: Design and methods of the
Gender Dysphoria Treatment in Sweden (GETS) study. Contemp Clin Trials Commun 2018;10:148-153.

7. Babor TF, Higgins-Biddle JC, Saunders JB, Monteiro MG: AUDIT: The Alcohol Use Disorders Identification Test, Guidelines for Use in Primary Care, 2nd ed. Geneva, Switzerland: World Health Organization, 2001.

8. Bradley KA, Boyd-Wickizer J, Powell SH, et al.: Alcohol screening questionnaires in women: A critical review. JAMA 1998;280:166-171.

9. American Psychiatric Association. Diagnostic and Statistical Manual of Mental Disorders, 4th ed. (DSM-IV). Washington, DC, American Psychiatric Association, 1994.

10. O'Connor EA, Perdue LA, Senger CA, et al.: Screening and Behavioral Counseling Interventions to Reduce Unhealthy Alcohol Use in Adolescents and Adults: An Updated Systematic Review for the U.S. Preventive Services Task Force. Rockville, MD: Agency for Healthcare Research and Quality (US); 2018 (Evidence Synthesis, No. 171.). Available at https://www.ncbi.nlm.nih.gov/books/NBK534916/ Accessed September 14, 2020.

11. Erol A, Karpyak VM: Sex and gender-related differences in alcohol use and its consequences: Contemporary knowledge and future research considerations. Drug Alcohol Depend 2015;156:1-13.

12. Agabio R, Pisanu C, Gessa GL, Franconi F: Sex differences in alcohol use disorder. Curr Med Chem 2017;24:26612670.

13. Gilbert PA, Pass LE, Keuroghlian AS, et al.: Alcohol research with transgender populations: A systematic review and recommendations to strengthen future studies. Drug Alcohol Depend 2018;186:138-146.

14. Coulter RWS, Blosnich JR, Bukowski LA, et al.: Differences in alcohol use and alcohol-related problems between transgender- and nontransgender-identified young adults. Drug Alcohol Depend 2015;154:251-259.

15. Watson RJ, Fish JN, McKay T, et al.: Substance use among a national sample of sexual and gender minority adolescents: Intersections of sex assigned at birth and gender identity. LGBT Health 2020;7:37-46.

16. Villarosa-Hurlocker MC, Schutts JW, Madson MB, et al.: Screening for alcohol use disorders in college student drinkers with the AUDIT and the USAUDIT: A receiver operating characteristic curve analysis. Am J Drug Alcohol Abuse 2020;1-15.

17. Moehring A, Rumpf HJ, Hapke U, et al.: Diagnostic performance of the Alcohol Use Disorders Identification Test (AUDIT) in detecting DSM-5 alcohol use disorders in the general population. Drug Alcohol Depend 2019;204: 107530.

18. Kerr-Corrêa F, Pinheiro FM Júnior, Martins TA, et al.: Hazardous alcohol use among transwomen in a Brazilian city. Cad Saude Publica 2017;33:e00008815.

19. Herrera MC, Konda KA, Leon SR, et al.: Do subjective alcohol screening tools correlate with biomarkers among high-risk transgender women and men who have sex with men in Lima, Peru? AIDS Behav 2017;21:253261.

20. Flentje A, Barger BT, Capriotti MR, et al.: Screening gender minority people for harmful alcohol use. PLoS One 2020; $15: \mathrm{e} 0231022$.

21. de Oliveira JB, Kerr-Corrêa F, Lima MC, et al.: Validity of alcohol screening instruments in general population gender studies: an analytical review. Curr Drug Abuse Rev 2014;7: 59-65. 
22. Fugitt JL, Ham LS, Bridges AJ: Undifferentiated gender role orientation, drinking motives, and increased alcohol use in men and women. Subst Use Misuse 2017;52:760772 .

23. Connolly D, Davies E, Lynskey M, et al.: Comparing intentions to reduce substance use and willingness to seek help among transgender and cisgender participants from the Global Drug Survey. J Subst Abuse Treat 2020;112:86-91.

24. Tan JY, Xu LJ, Lopez FY, et al.: Shared decision making among clinicians and Asian American and Pacific Islander sexual and gender minorities: An intersectional approach to address a critical care gap. LGBT Health 2016;3:327334.

25. Glynn TR, van den Berg JJ: A systematic review of interventions to reduce problematic substance use among transgender individuals: A call to action. Transgend Health 2017; 2:45-59.

26. Gonzalez CA, Gallego JD, Bockting WO: Demographic characteristics, components of sexuality and gender, and minority stress and their associations to excessive alcohol, cannabis, and illicit (noncannabis) drug use among a large sample of transgender people in the United States. J Prim Prev 2017;38:419-445.

Address correspondence to: Alex S. Keuroghlian, MD, MPH National LGBTQIA+ Health Education Center Division of Education and Training The Fenway Institute Fenway Health 1340 Boylston Street Boston, MA 02215

USA

E-mail: akeuroghlian@partners.org 